\title{
A Right Against Risk Imposition and the Problem of Paralysis
}

Holm, Sune Hannibal

Published in:

Ethical Theory and Moral Practice

DOI:

10.1007/s10677-016-9697-6

Publication date:

2016

Document version

Publisher's PDF, also known as Version of record

Citation for published version (APA):

Holm, S. H. (2016). A Right Against Risk Imposition and the Problem of Paralysis. Ethical Theory and Moral Practice, 19(4), 917-930. https://doi.org/10.1007/s10677-016-9697-6 


\section{A Right against Risk-Imposition and the Problem of Paralysis}

\section{Sune Holm}

Ethical Theory and Moral Practice

An International Forum

ISSN 1386-2820

Volume 19

Number 4

Ethic Theory Moral Prac (2016)

19:917-930

DOI 10.1007/s10677-016-9697-6

Volume 19 No. 4 August 2016

ISSN 1386-2820

\section{Ethical Theory and Moral Practice}

An International Forum

Editors-in-Chief

Robert Heeger

Albert W. Musschenga 
Your article is protected by copyright and all rights are held exclusively by Springer Science +Business Media Dordrecht. This e-offprint is for personal use only and shall not be selfarchived in electronic repositories. If you wish to self-archive your article, please use the accepted manuscript version for posting on your own website. You may further deposit the accepted manuscript version in any repository, provided it is only made publicly available 12 months after official publication or later and provided acknowledgement is given to the original source of publication and a link is inserted to the published article on Springer's website. The link must be accompanied by the following text: "The final publication is available at link.springer.com". 


\title{
A Right against Risk-Imposition and the Problem of Paralysis
}

\author{
Sune Holm ${ }^{1}$
}

Accepted: 3 February 2016 / Published online: 16 February 2016

(C) Springer Science+Business Media Dordrecht 2016

\begin{abstract}
In this paper I examine the prospects for a rights-based approach to the morality of pure risk-imposition. In particular, I discuss a practical challenge to proponents of the thesis that we have a right against being imposed a risk of harm. According to an influential criticism, a right against risk-imposition will rule out all ordinary activities. The paper examines two strategies that rights theorists may follow in response to this "Paralysis Problem". The first strategy introduces a threshold for when a risk-imposition is a rights violation. The second strategy drops the claim that rights are absolute and maintains that all rights infringements generate compensation duties. It is argued that both strategies face significant practical problems of their own and that the Paralysis Problem seems fatal for a right against riskimposition in the absence of an adequate account of the morally relevant threshold risk.
\end{abstract}

Keywords Ethics $\cdot$ Compensation $\cdot$ Consent $\cdot$ Rigths $\cdot$ Risk $\cdot$ Threshold

Do you have a natural right that I not read Crime and Punishment if this would cause a smallish increase in the probability that I might one day rob and bludgeon you? ${ }^{1}$

\section{Introduction}

In this paper I examine the prospects for a rights-based approach to the morality of pure riskimposition. In particular, I will discuss a practical challenge to proponents of a rights-based ethics of risk-imposition. According to Hayenhjelm and Wolff "it seems impossible to argue

${ }^{1}$ Railton (1985).

Sune Holm

suneh@hum.ku.dk

1 Philosophy Section, Department of Media, Cognition, and Communiction, University of Copenhagen, Copenhagen, Denmark 
that there is an absolute right not to be subject to any risk to which one has not consented, for this would seem to rule out virtually all action" (2011, p. e37). I will follow Hayenhjelm and Wolff and refer to this as the "Paralysis Problem". Hayenhjelm and Wolff characterize the Paralysis Problem as "the central philosophical problem" about the permissibility of riskimposition. This observation can, I think, be backed up by pointing out that the problem is a staple of discussions of risk-imposition during the last four decades. Thus Charles Fried (1970, pp.192-193 and 1978, pp. 18-19) raises the worry about paralysis, it is noted by Nozick in his discussion of risk (Nozick 1974, pp. 73-78), and it has been discussed continually in the literature on permissible risk-imposition since then (see e.g. Hanfield and Pisciotta 2005; Hansson 2013, ch. 6; Kagan 1989, pp. 87-88; McCarthy 1997, p. 208; Schroeder 1986, pp. 526-527; Teuber 1990, p. 246). While the problem concerns a practical consequence of "the Risk Thesis", the claim that individuals have a right against risk-imposition, it is generally claimed to show that the Risk Thesis is "contradictory and incoherent" (Schroeder 1986, p. 527), "reduced to absurdity" (Kagan 1989, p. 88), and should be rejected as false (McCarthy 1997, p. 208). In short, it seems crucial for the rights based account of the morality of riskimposition to respond to the Paralysis Problem.

The paper makes several distinctive contributions to the discussion of the rights theoretical approach to the morality of risk. First, it structures the central arguments of the debate in terms of two strategies that rights theorists may follow in response to the Paralysis Problem. The first strategy to be considered is to weaken the claim that individuals have a right against risk-imposition by introducing a threshold for when a risk-imposition is a rights violation. The second strategy to be examined holds on to a strong claim against risk-imposition and make adjustments elsewhere in the rights theoretical framework. Second, thinking in terms of these two strategies provides an excellent basis for discussing the important defense of the Risk Thesis in the face of the Problem of Paralysis presented in McCarthy (1997). Finally, the paper presents two original arguments against McCarthy's theory, and thus moves the debate about the morality of risk forward by showing that the most recent and so far undisputed in-depth defense of the Risk Thesis does not provide an adequate response to the Problem of Paralysis. Finally, the paper connects the philosophical discussion of the morality of risk-imposition to issues concerning standard practice in negligence law.

Before I delve into the Problem of Paralysis, I should note that there is another related problem that arises in connection with the Risk Thesis, and which I will not discuss in this paper. What might be called "the Proliferation Problem" concerns the fact that the Risk Thesis seems to entail a burgeoning of trivial rights violations and this may be thought to diminish our respect for rights in general. This problem is also a serious one. While a full assessment of a right against risk-imposition will also include a discussion of the Proliferation Problem I will leave it aside as the topic of another paper. Here my focus is on the Problem of Paralysis. ${ }^{2}$

The plan of the paper is this. In section 2 I introduce the notion of a pure risk-imposition, the Risk Thesis, and the Problem of Paralysis. In section 3 I assess the strategy of circumscribing the Risk Thesis by introducing a threshold risk. Then in section 4 and 5 I consider the strategy of maintaining the undiluted version of the Risk Thesis. I conclude that the Paralysis Problem presents a formidable obstacle for

\footnotetext{
2 Thomson rejects the Risk Thesis due to the Proliferation Problem (1990, p. 245). Zimmerman (2006) and McCarthy (1997) do not think proliferation is an adequate reason for rejecting the Risk Thesis.
} 
proponents of the Risk Thesis though I suggest that the threshold account may be able to handle the paralysis problem if the relevant threshold can be determined.

\section{Pure Risk-Imposition, the Risk Thesis, and the Problem of Paralysis}

Ordinary activities of everyday life impose risks of harm on other people, and it thus seems pertinent to consider how moral theories approach the question of when it is permissible for an individual to impose a pure risk of harm on another individual. Thomson introduces the notion of "a pure risk-imposition" presenting the following case:

Suppose A played Russian roulette on B. B has ground for complaint against A even if $\mathrm{B}$ was caused no harm, and even if B was unaware of what happened, so that he was caused no fear or discomfort. The ground for complaint lies in the fact that A imposed as risk of death on B (Thomson 1985, p. 126).

In this case A imposes a pure risk of harm on B because no actual harm results from the risk-imposing action. ${ }^{3}$ Rights theories arguably come up short when challenged to account for the distinction between permissible and impermissible pure risk-imposing actions. For rights theorists to be able to say that some pure risk-imposing actions are impermissible, they must put forward the following thesis:

The Risk Thesis We have a right that other people not impose risks of harm upon us.

However, if the Risk Thesis is true, then arguably most of the ordinary activity that people engage in will turn out to be impermissible. Toasting bread, making coffee, and driving to work are activities that impose pure risks on other people. If doing so constitutes a rights infringement, then people are not permitted to do any of these things. Thus the Risk Thesis generates the Paralysis Problem. To deal with the Paralysis Problem risk theorists may opt for one of two possible strategies. One strategy is to make room for permissible risk-impositions by somehow circumscribing the right against risk-imposition. This strategy will aim at enabling rights theorists to permit ordinary risk-impositions by showing that they do not qualify as rights infringements. An alternative strategy is to maintain that all riskimpositions are rights infringements and account for when such rights infringements are permissible. In other words, the first strategy aims to show that ordinary risk-impositions are not rights infringements and thus permissible, the second aims to show that while all riskimpositions are rights infringements some of them are permissible. I will discuss these two strategies in turn.

Before I move on, a brief comment on the relation between risk-imposition and harm. Legal philosophers have proposed that a right against risk-imposition can be grounded in the fact that risk impositions are a kind of harm (Finkelstein 2003; Oberdiek 2012). For example, Oberdiek produces an important argument for the conclusion that the moral significance of risking resides in the fact that it results in a "nonmaterial negative effect", more precisely a setback to people's interest in autonomy, and thereby constitutes an actual harm (Oberdiek 2012, p. 342).

\footnotetext{
3 Thus B might be or become aware of a pure risk-imposition. Pure risk-impositions of which the risk-imposed individual never becomes aware may be called "super-pure risk-impositions." However, I focus on pure riskimpositions.
} 
However, in this paper I follow Thomson (1986) and McCarthy (1997) and assume that a riskimposition is not itself a harm.

\section{Weakening the Risk Thesis}

\subsection{The Threshold Risk Thesis and the Indifference Thesis}

Taken at face value, the Risk Thesis seems to lead to paralysis. In order to avoid paralysis rights theorists may try to weaken the Risk Thesis by circumscribing the risky actions that it targets. One way to do so is to suggest that below some threshold a risk-imposition does not amount to a rights infringement. However if the risk imposed is sufficiently great it will infringe the right against risk-imposition and thus be impermissible. This line of argument can be characterized as suggesting a modified version of the Risk Thesis:

Threshold Risk Thesis We have a right that other people not impose risks of harm upon us above threshold R.

Arguably the Paralysis Problem can be avoided if we accept the Threshold Risk Thesis. If accepted, the thesis ensures that people are prohibited from imposing unacceptably high risks on others, but are permitted to perform ordinary risk-imposing actions such as toasting bread and driving cars. The threshold grants people a reasonable degree of freedom and autonomy, and it restricts the level of risk that may permissibly be imposed on them.

Proponents of the Threshold Risk Thesis also accept the following thesis ${ }^{4}$ :

Indifference Thesis If doing $\mathrm{F}$ has probability $\mathrm{P}$ of causing outcome $\mathrm{E}$ and doing $\mathrm{F}^{*}$ has probability $\mathrm{P}$ of causing outcome $\mathrm{E}$, then there would be no grounds for permitting doing $\mathrm{F}$ and not permitting doing $\mathrm{F}^{*}$ reasoning exclusively on the basis of risk magnitude.

To illustrate, if toasting bread and playing Russian Roulette on my neighbour imposes the same probability of killing him, then there would be no reason to prohibit one and allowing the other reasoning in terms of risk magnitude only. While the Indifference Thesis is plausible, I think there are strong objections to the Threshold Risk Thesis based on moral features of risk-imposition.

\subsection{More than Magnitude Matters: Normative Considerations}

An immediate worry about the Threshold Risk Thesis is that its proponents must tell a story about how the threshold is to be fixed and there is no straightforward and uncontroversial answer to this question. However, for the purposes of this paper I will grant proponents of the Threshold Risk Thesis a threshold $\mathrm{R}$ and focus on what I take to be a deeper worry, namely that there are some risky actions which are equal in terms of risk magnitude and still our moral intuition suggests differentiating between them by means of some normative considerations other than risk magnitude. ${ }^{5}$ To illustrate this claim consider the following two cases:

\footnotetext{
${ }^{4} \mathrm{I}$ am indebted to an anonymous referee for emphasizing this point.

${ }^{5}$ In connection with sort of problem Nozick proposes to distinguish between productive/non-productive actions (Nozick 1974, ch. 4) and Railton (1985) discusses the merits of distinguishing between intentional and nonintentional actions.
} 
Toast When turning on my toaster I impose a risk on people in my building below threshold R.

Below R Russian Roulette Playing a game of Russian roulette on you with an n-chamber revolver while you are asleep I impose a risk on you below threshold R.

In both these cases, the risk imposed is below the threshold. Hence, we should give the same moral evaluation of the two cases, unless some other feature of them justifies different moral assessments. Still, the objection goes, playing Russian Roulette is impermissible even if the risk imposed is below the threshold. In other words, it is not the size of the risk that matters, but the risk-imposition as such. So how can proponents of the Threshold Risk Thesis maintain that Toast is a case of permissible risk-imposition and Below R Russian Roulette is not given that the risk imposed in the two cases is below $\mathrm{R} ?^{6}$

In response to this problem advocates of the Threshold Risk Thesis may try to justify treating the two cases differently by appealing to the distinction between intending and merely foreseeing a risk-imposition. When toasting bread I do not intend to impose a risk on other people, it is merely a foreseen side-effect of my toasting efforts. On the other hand, when playing Below R Russian roulette on my sleeping neighbor, I intend to impose the risk of death on her.

I think there is good reason to reject the appeal to intention. Assume that we think it is intrinsically wrong to kill an innocent person. Are intentions relevant for the wrongness of this action? It seems not, for the following reason: in case we consider killing an innocent to be intrinsically wrong adding that the action is done intentionally does not turn a morally neutral act into an intrinsically wrong act. Rather it is the other way around. It is wrong intentionally to kill an innocent because it is wrong to kill an innocent full stop. ${ }^{7}$ Thus, if it is a rights infringement and thus morally wrong to intentionally impose a risk of harm on someone, then this is not because of the fact that the risk-imposition is intended, but because of the fact that what is intended is a rights infringement. In short, the appeal to intention should be rejected. ${ }^{8}$ However, if intentions do not make a difference to the permissibility of an action, then rights theorists proposing the Threshold Risk Thesis cannot prohibit Below $\mathrm{R}$ Russian roulette cases by reference to the fact that the agent intends to impose harm. Below $\mathrm{R}$ Russian roulette and toasting bread must receive the same moral evaluation relative to the size of the risk they impose.

However, I think proponents of the Threshold Risk Thesis may provide an adequate account of the moral difference between Toast and Below R Russian Roulette. Consider the uncontroversial case of toasting bread. In ordinary circumstances the risk-imposition resulting from toasting bread is a foreseen side-effect of the action not its aim. However, consider a person who toasts bread as a means to impose a small risk of harm on his neighbor. In this case we do not conclude that toasting bread is a wrongful action. Rather, the moral wrongness resides in the reasons that the agent has for performing the action. In other words, in some cases an agent may be blameworthy for performing an otherwise permissible risk-imposing action due to the agent's reasons for acting.

\footnotetext{
${ }^{6}$ Nozick's reply to this problem is to suggest two features of Russian roulette that explains why it is prohibited despite imposing a below threshold risk: 1) Russian roulette is not a socially valuable activity, not productive. 2) Russian roulette is not an ordinary and important feature of people's lives (1974, ch. 4).

${ }^{7}$ This line of argument can be found in Railton (1985).

${ }^{8}$ See Scanlon (2008) for important discussion of the relevance of intentions for the moral assessment of an action.
} 
We can now see that the distinction between blameworthy and non-blameworthy toasting can be generalized as a distinction between blameworthy and non-blameworthy risk-imposition. Assuming that actions resulting in risk-impositions below $\mathrm{R}$ are not rights infringements and hence not morally impermissible, then Below R Russian Roulette will not be wrong due to the risk imposed by that act. What is morally wrong about it is that the game involves a blameworthy motivation for performing a risk-imposing action. In sum, I think proponents of the Threshold Risk Thesis can respond to the Below R Russian Roulette case by pointing out that it is a case of blameworthy risk-imposition, not a case where the risk-imposition as such is impermissible.

Still, there is another problematic feature of the Threshold Risk Thesis, which comes out from considering a more true-to-life case suggested by McKerlie (1986):

Toxic Waste I own a factory that as a bi-product produces toxic waste. I have two options as to how to dispose of the toxic waste. One option is to bury it underground thereby imposing a risk on my neighbour that the toxic waste will seep into his property and cause harm. The risk is above $\mathrm{R}$ and thus this option constitutes a infringement of my neigbour's right against riskimposition. The second option is to dump the toxic waste in a river bordering my property. This option imposes a risk of harm on all the people living along the river. However, the risk imposed on each is well below $\mathrm{R}$ and hence no rights are infringed by this option.

In general the Threshold Risk Thesis entails that a single individual is permitted to perform actions that impose a below threshold risk on other individuals even if the action results in a close-to-1 probability that someone will suffer a severe harm. Thus if the toxic waste dumped in the river affects a million people imposing a one-in-a-million risk of death to each it will not infringe any individual's rights and hence be permitted on the Threshold Risk Thesis. Several authors criticize the Threshold Risk Thesis for entailing that no rights are infringed when the risk is spread out thinly on many individuals (e.g. McCarthy 1997; McKerlie 1986; Railton 1985). Rights theorists may try to meet this criticism either by showing that dumping the waste in the river does infringe a right and thereby avoid the allegedly repugnant conclusion, or they may argue that the fact that no rights are infringed in this case is not such a repugnant conclusion after all.

One way to argue that dumping the waste in the river does involve a rights infringement is to point out that because someone will actually be harmed, there is someone whose right is being infringed when dumping the waste in the river. However, this response does not get to the problem. The problem concerns infringement of the right not to be imposed a risk of harm, not the right not to be imposed a harm. In other words, the relevant perspective is ex ante not ex post, and ex ante there is no impermissible risk-imposition on anyone. ${ }^{9}$

What is the prospect of maintaining that it is not repugnant to conclude that no rights are infringed when spreading the risk thinly over many people? First of all, a central motivation for rights theories is that they are non-consequentialist: sometimes the morally right thing to do is something that does not maximize the overall good. It is thus a core feature of rights theories that it is more important not to infringe the rights of an identified individual than to ensure that nobody gets harmed. In the case at hand, the expected harm resulting from the second option is higher than the expected harm resulting from the first, so if our concern was consequentialist,

\footnotetext{
${ }^{9}$ Importantly, if we interpret risk-imposition along the lines of Oberdiek (2012), then there will be a rights violation ex ante in this case. Thanks to an anonymous referee for pointing this out.
} 
then we should pick the first option. However, an important driving force behind rights theories is that we ought not infringe people's rights even when it may produce more good overall. In short, given its non-consequentialist motivation, it does not seem like a good argument against the rights theory that it entails that we should opt for the solution that has a larger expected harm. This is exactly what the theory is meant to permit.

In conclusion, if we grant a threshold, I do not think that the objections I have considered are conclusive. The objection that the Threshold Risk Thesis cannot account for the wrongness of Below R Russian Roulette is not convincing once we consider the independent distinction between the moral evaluation of an action and of the reasons or motives for performing the action. And with regard to the Toxic Waste case the objection that the option of spreading the risk thinly should not make dumping the waste permissible is, I think, a controversial implication of the Threshold Risk Thesis. Still, it is not clear that it constitutes a nonquestion-begging objection to rights theorists since they do not accept consequentialist aggregative reasoning. In short, I submit that the Threshold Risk Thesis has the tools for providing an adequate response to the objections considered in this section. Still, as already noted, the Threshold Risk Thesis does face a significant practical challenge in determining a risk threshold.

\section{Maintaining the Risk Thesis: Consent}

An alternative to the strategy of weakening the Risk Thesis by introducing a threshold is to embrace it, thereby making all risk-impositions rights infringements, and then show that such infringements are permissible when certain conditions are met. A standard way to do so is to appeal to the notion of consent. If a person consents to a risk-imposition from some activity, then it is permissible to perform that activity, despite the fact that it infringes the person's right. Thus, if the neighbor to my factory explicitly consents to being imposed the risk that comes from my burying the toxic waste underground beforehand, then I am permitted to do so.

One might debate when consent to a rights infringement is legitimate and whether some consented-to infringements should nevertheless be prohibited. However, I think that the most pressing issue arising from appeal to consent is that the scope of individuals on which ordinary activities impose a risk makes it practically unfeasible to seek explicit consent from all whose right against risk-imposition is infringed. In other words, there is a practical problem for appealing to the notion of consent, namely that it is simply not always practically possible to (i) determine who to ask for consent, and (ii) to seek out those who are affected by a riskimposing action (McCarthy 1997, p. 216). E.g. our actions also impose risks on future individuals from whom it is obviously impossible to acquire explicit consent. In addition to this practical impasse, it also seems to be conceptually impossible to consent to a risk imposition. A risk-imposition is, by definition, non-consensual. Thus, in those cases where practical consent is actually obtained, we no longer have a case of risk-imposition. Rather such cases are ones in which an agent decides to take a risk.

For those rights theorists taking the consent line in response to the Paralysis Problem it will be tempting to propose schemes of ex post compensation. This would amount to a form of hypothetical consent in that it is assumed that those whose right against risk-imposition has been infringed would have agreed to the risky activity ex ante if offered certain benefits. There will be two sub-groups of the group of individuals whose right is infringed: one group will 
include all and only those individuals who are actually harmed by the risky activity, the other group will include all and only those risk-imposed individuals who are not caused any actual harm from the risky activity. With regard to the first group the compensation should be such that the victim had been indifferent ex ante when given the choice between suffering the actual harm and getting compensation and not suffering the actual harm. With regard to the second group the compensation must be a benefit that would, ex ante, make the person indifferent to the option of the risk-imposition plus benefit and not being exposed to the risk at all. ${ }^{10}$ Still, there are both practical and theoretical problems with appeal to hypothetical consent.

From a practical perspective, determining who should get what, and in particular, which future individuals should get what, because of the risk imposed on them by what I do today, seems practically impossible. In other words, simply requiring risk-imposers to calculate how much they should provide in compensation to those put at risk according to their hypothetical consent will be such an enormous task that it would lead to the Paralysis Problem. From a theoretical perspective hypothetical consent does not cohere well with the anti-paternalistic aspect of rights theories (Railton 1985, pp. 114-115). In the tradition from Locke, rights theories emphasize the importance of letting people decide for themselves instead of saying that "had you been asked beforehand and where you fully rational and well-informed, then you would have consented to the risky activity." Finally, it is worth noting that hypothetical consent is not accepted in relation to property rights. Rights theorists do not generally think that it is permissible to steal and appeal to hypothetical consent and compensation. I am not permitted to steal your money to invest them and then give you the money back with interests just because you would have hypothetically consented to this arrangement. Thus the appeal to consent, whether explicit or hypothetical, does not seem to enable the rights theorist to maintain the Risk Thesis and avoid the Paralysis Problem. ${ }^{11}$

Summing up, I submit that proponents of the Risk Thesis, who try to make room for permissible risk-impositions by appealing to the notion of hypothetical consent, face a number of very strong objections. Thus I conclude that this strategy for dealing with the Paralysis Problem does not seem promising compared to the proposal of the Threshold Risk Thesis.

\section{Maintaining the Risk Thesis: Trade-Offs and Compensation}

So far I have assumed that all rights infringements are impermissible, which is to say, I have assumed that rights are absolute. However, McCarthy (1997) defends the Risk Thesis in part by arguing that rights are not absolute: rights may permissibly be infringed when the good gained by the infringement sufficiently outweighs the harm incurred by infringing the right. In this section I first present McCarthy's case against absolutism. I then take up McCarthy's account of compensation. Unlike the Threshold Risk Thesis, all ordinary risk-impositions will be rights infringements and thus generate compensation duties. I argue that McCarthy's Natural Lottery Rule for governing compensation claims should be rejected and I conclude that McCarthy's proposal leads to a form of paralysis.

\footnotetext{
${ }^{10}$ There are of course limits to compensation for risk-impositions. If you die, I cannot compensate you. I will leave this problem aside and merely note that this shows that compensation is not clearly a way of avoiding tough restrictions on risky activities.

${ }^{11}$ Notably proponents of the Threshold Risk Thesis also introduce a consideration that is not traditionally accepted with respect to property rights. It is not as if what I steal must be above some threshold value in order for my theft to be a rights infringement. Stealing a hairpin is as impermissible as stealing a car.
} 
In order to establish his argument against absolutism McCarthy presents the following case:

Stealing Drugs Suppose you are away on vacation and I suddenly and unexpectedly need a small amount of the drug you have plenty of to save my life. It is quite clearly permissible for me to take that amount of the drug, despite your having the right that I not take it (you own it). But we cannot then maintain that your right that I not take it is absolute.

Absolutists who recognize that it is "clearly permissible" to steal in this case ${ }^{12}$ may try to recognize the permissibility of my stealing the drug by making one of two replies:

1. They can specify that the right you have against my stealing is the right that I do not impermissibly steal the drug.

2. They can point out that you only have the right against my stealing the drug in certain circumstances. That is to say, in some circumstances, the right against my stealing the drug is absent.

The first reply simply amounts to saying that I am permitted to take the drug because I am permitted to take it. Your possession of an ownership right in the drug does not figure in the explanation of why it is permissible for me to steal it. The second reply is not convincing either. In the case at hand, we would think that I am under a duty to compensate you for the theft. However, the duty to compensate you arises from the fact that you had a right against my stealing your drug. Hence, these are not circumstances in which there is no rights infringement, which contradicts the second reply. So the case is one in which there is a permissible rights infringement. Hence rights are not absolute. It is sometimes permissible to infringe them. The next question is under what conditions rights infringements are permissible?

The most obvious reason to permit a rights infringement such as the one in Stealing Drugs is presumably that something good comes out of it. More specifically, it seems that the good resulting from the rights infringement is sufficiently large to justify the burden suffered by the individual whose right is infringed. McCarthy calls this "the Trade-off Idea" (McCarthy 1997, p. 209, see also Thomson 1990, ch. 6):

Trade-Off Idea A rights infringement is permissible if the good that would come of the infringement sufficiently outweighs the burden of the infringement to the bearer of the right. ${ }^{13}$

How should we determine whether the good resulting from a rights infringement sufficiently outweighs the burden imposed on the individual whose right against risk-imposition is being infringed? McCarthy proposes a sliding threshold account of when a good is sufficiently large. The burden of being imposed the risk is the product of the size of the possible harm and the possibility that it results from the risky action. To illustrate, assume that we have a unit by which we measure the size of harm such as being blinded or killed. Being blinded amounts to 100 units. Then imposing a risk of 0.1 of blinding Abby will impose a burden of 10 units on

\footnotetext{
${ }^{12}$ It is not at all clear to me that strictly non-consequentialist rights theorists should accept this case as one in which stealing is "clearly permissible." However, I will not take issue with McCarthy's argument against absolutism in this paper.

${ }^{13}$ It is notable that the Trade-off Idea is not limited to the claim that the good produced by the rights infringement sufficiently outweighs the burden. In so far as the Trade-off Idea is the one presented by Thomson (1990, ch. 6), it involves a distribution requirement according to which the good is not an aggregate of minor goods to many distinct individuals. The sufficiently large good must be obtained by a single individual: the sufficiently large good outweigh the burden of the bearer of the right only if there is at least one person whose benefit is sufficiently greater than the burden.
} 
her. Moreover, Abby's burden from being imposed this risk of being blinded will be equivalent to Bobby's burden when imposed a 0.01 of a harm of 1000 units and equivalent to imposing a risk of 1 (certain) on Charlie that he suffers a harm of 10 .

We can now explicate the idea that there is a sliding threshold of how much good must be expected to result in order for a risk-imposition to be permissible. ${ }^{14}$ The expected benefit of the rights infringement must sufficiently outweigh the expected burden where these values are understood in terms of the notion of expected utility.

Combining the Risk Thesis with the Trade-off Idea McCarthy concludes that the Paralysis Problem can be avoided:

(...) [B]y allowing that there is a sliding scale of the good that is needed to make a rights infringement permissible, with, in particular, relatively little good needed to make permissible infringements which hardly make the bearer of the right any worse off at all, we can account for our understanding of the permissibility of a very wide range of risk-impositions (1997, p. 213).

In addition to the Risk Thesis and the Trade-off Idea McCarthy accepts:

The Compensation Idea Other things being equal, if one person infringes the right of another, then, very roughly, the infringer is under a duty to compensate the bearer of the right. ${ }^{15}$

If we accept the Compensation Idea and the Risk Thesis, then all risk-impositions come with a duty to compensate. To some this conclusion appears problematic. Ordinarily duties to compensate arise when an individual is actually harmed, not when the individual is merely imposed a risk of harm. ${ }^{16}$ So the challenge to the Risk Thesis presented by compensation is that rights infringements are sufficient for there being compensation duties, but not all risk-impositions result in compensation duties. Hence, in opposition to the Risk Thesis, not all risk-impositions can be rights infringements. Call this "the Compensation Problem."

McCarthy approaches the Compensation Problem by taking a closer look at what it would be to compensate for a risk-imposition. What sort of compensation scheme should a proponent of the Risk Thesis propose? McCarthy suggests that there are two compensation rules to choose between:

Direct Payment Rule If an agent imposes a risk of harm on another, then he or she is under a duty to compensate the risk bearer by making a direct payment.

\footnotetext{
${ }^{14}$ In relation to the notion of a sliding threshold I think it is worth noting that Kagan (1989, pp. 87-91) thinks that appeal to a sliding threshold is the only solution to the paralysis problem open to the rights theorist. Furthermore Kagan points out that a sliding threshold may be determined in a number of ways. E.g. in contrast with McCarthy, Kagan suggests that "an act with twice the risk of inflicting a given harm as a second act need not have exactly twice as high a threshold (...)," and that the idea of a sliding threshold does not imply that acts with identical expected harms (size of harm $\times$ probability of inflicting that harm) must have identical thresholds. That is, an act with a high risk of inflicting a small harm need not have a low threshold, even though the expected harm is the same as for some other act with a small risk of inflicting a great harm which does have a low threshold. ${ }^{15}$ Other things are not equal if the risk-imposer is ignorant. In that case it is not clear that a duty to compensate arises. So the focus here will be on cases in which the risk-imposer knows about the risk being imposed.

${ }^{16}$ Thomson (1986, pp. 154-172) rejects the Risk Thesis because compensation duties do not seem to be generated by pure risk-impositions. McCarthy (1996) argues that there are cases in which compensation duties are "very closely linked" to pure risk-impositions.
} 
Natural Lottery Rule If an agent imposes a risk of harm on another, then he or she is under a duty to pay the risk bearer compensation for the harm if the risk bearer suffers the harm as a result of bearing the risk, and nothing otherwise.

Whether we apply one or the other rule to agents who impose risks on others, the following is the case:

If the agent is guaranteed to comply with whatever duties arise from that rule, then the risk bearer is fully compensated for bearing the risk (McCarthy, p. 221).

More specifically, proponents of the Risk Thesis can maintain that that thesis is consistent with the Compensation Idea by pointing out that for any agent, who imposes a risk on others, it is the case that the agent is subject to a rule such that if the agent complies with the rule, then the risk bearers are guaranteed to be fully compensated for the risk-imposition. ${ }^{17}$ Still, an important assumption of this reply is that it is the expected harm of the risk-imposing action that determines the size of the compensation. However, it will be very difficult if not impossible always to calculate the expected harm of a risk-imposing action, which is necessary for applying the Direct Payment Rule. Hence, McCarthy suggests that there is reason to determine the compensation for a risk-imposition only if an actual harm results, which is what the Natural Lottery Rule suggests.

With respect to the Natural Lottery Rule, one problematic implication may be thought to be that it makes the actual consequences of the risky action irrelevant for the size of the compensation. However, I do not think this is a strong objection to the Natural Lottery Rule. If the compensation is for the risk-imposition, then an ex ante calculation of the burden to be compensated is appropriate. However, I think there is another aspect of the Natural Lottery Rule that poses a significant problem for accepting this rule.

According to the Natural Lottery Rule cases of pure risk-impositions are rights infringements generating a duty to compensate. However, when the risky actions do not result in actual harm, the risk-imposer does not have to actually pay out any compensation. This scheme is attractive because it avoids having to calculate compensation for all cases of pure riskimpositions. Only a small subset of all risk-impositions will actually cause harm. However, if, for some reason, the Natural Lottery Rule must be rejected, then accepting the Risk Thesis entails a version of the Paralysis Problem because the only alternative compensation rule, Direct Payment Rule, is practically impossible to apply.

A first point to note with respect to the Natural Lottery Rule is that, in contrast with the Direct Payment Rule, it entails that compensation is only to be paid in cases where actual harm occurs. This reveals a morally relevant discrepancy between the two rules. What makes the Direct Payment Rule seem justified (even if impractical) is that compensation is owed when rights are infringed without consent. The Natural Lottery Rule, if accepted, does not honour this idea, since it entails that individuals whose right against risk-imposition is violated do not have a claim to receive compensation, even if some individual is under a duty to compensate them. Note that the Natural Lottery Rule is not the idea that we pool together the compensation owed for risk-impositions in order to pay those who actually get harmed compensation for being harmed. The idea is not that all risk-imposers pay a risk premium for the risk they

\footnotetext{
${ }^{17}$ Of course, there is no guarantee that agents always comply with such a rule, but that is a different matter. Note also, that the sort of case I will discuss here is not the sort of case where the risk imposed would be hypothetically consented to by the person on which the risk is imposed. That would amount to an agent accepting a risk-pluscompensation package or to taking a risk.
} 
impose, which is then distributed to those who suffer actual harm. Those being harmed only get compensation as calculated ex ante, i.e. the size of the compensation is what would have made them prospectively as well off as they had been had they not been imposed the risk. This has an important consequence, which reflects a morally important discrepancy between the Natural Lottery Rule and the Direct Payment Rule.

First, assuming that not all risk-impositions result in actual harm, the total amount of compensation paid on the basis of the Natural Lottery Rule will be lower than the total amount that would be paid out on the Direct Payment Rule. In other words, the amount owed on the basis of the compensation duties incurred will not equal the amount paid out in compensation on the basis of the Natural Lottery Rule. The Natural Lottery Rule can thus be said to entail a compensation deficit. Insofar as compensation is a matter of making up for a moral wrong, even when this wrong is permissible, the Natural Lottery Rule entails a moral deficit compared to the Direct Payment Rule. Hence, if one thinks that the Direct Payment Rule is a theoretically adequate even if impractical way of determining compensation claims, then one has good theoretical reason to reject the Natural Lottery Rule as inadequate. ${ }^{18}$

McCarthy might reply that the Natural Lottery Rule should be accepted on pragmatic grounds. Clearly the Direct Payment Rule will not be realizable, so we should work with the best alternative, which is the Natural Lottery Rule. However, defending the Natural Lottery Rule on pragmatic grounds is also problematic. First, it is worth noting that McCarthy does not include that compensation has to be "practically feasible" as an additional qualification to be captured by the "other things being equal" clause in his statement of the Compensation Idea. Unlike ignorance, the practical infeasibility of honoring a compensation duty does not cancel or efface it. Compensation duties linger despite the fact that they cannot be met. So coming up with an alternative to the Direct Payment Rule amounts to proposing a criterion for determining which lingering compensation duties must be settled. The Natural Lottery Rule proposes such a criterion: When there is actual harm as a result of the risk-imposition. However, at no point does McCarthy give a justification for why actual harm should serve as the criterion for settling compensation claims. As a matter of fact, it seems wholly arbitrary to suggest that actual harms determine when compensation for a risk-imposition should be settled, unless one thinks that actual harm is what matters about risk-impositions. Why not propose the following rule as the basis for identifying a practically feasible subset of risk-impositions that require determination of compensation:

Natural Redhead Rule If an agent imposes a risk of harm on another, then he or she is under a duty to pay the risk bearer compensation for the harm if the risk bearer is a natural redhead, and nothing otherwise.

Presumably the Natural Redhead Rule is not practically impossible to apply. It is, however, completely arbitrary from a moral point of view, and thus inadequate as a rule for determining compensation. In other words, a pragmatic grounding of a rule for when compensation claims should be settled must be justified by more than its practical feasibility, but McCarthy has not provided such a justification for the Natural Lottery Rule. Perhaps a better rule would be one according to which we should simply settle as many compensation claims as practically possible, but then some non-arbitrary rule for which compensation claims to determine must be identified. Note that in this case we are discussing a rule for determining compensation

\footnotetext{
${ }^{18}$ Metaphorically speaking this difference between the two rules may be said to be like the difference between paying directly for participating in a lottery and only wanting to pay for a lottery ticket if one wins.
} 
claims. Hence, we cannot suggest that the ones to be determined should be the ones where a large compensation is owed, since we will not know which ones are large before we embark on the project of determining compensation claims. In short, McCarthy has not provided a pragmatic justification of the Natural Lottery Rule.

My criticism of McCarthy relates to an interesting discussion concerning the compatibility of McCarthy's theory with negligence law, where the norm is that one has to cause harm in order to be under a duty to compensate. By proposing the Natural Lottery Rule, McCarthy seems to make his account fit this practice better. Thus Handfield and Pisciotta writes that "implementing the natural lottery rule is superficially identical to the standard practice of negligence law" (2005, p. 392). However, making his account compatible with a practice based on actual harm as the basis for compensation duties does not justify selecting actual harm as the defining feature of the subset of risk-impositions for which compensation will be determined. As a matter of fact, my criticism of McCarthy may be taken to point out that if we accept the Risk Thesis and the Compensation Idea, then the standard practice of negligence law based on actual harm ought to be revised. ${ }^{19}$

In conclusion, I submit that there are two good reasons to reject the Natural Lottery Rule. First, it differs significantly from the Direct Payment Rule in that it entails a compensation deficit. Second, no justification has been put forward for why this rule should be chosen as the best pragmatic solution to the practical problem of determining compensation claims. In particular, there might be compensation rules that are both practically feasible and entails a smaller compensation deficit than the Natural Lottery Rule. Hence, unless McCarthy produces another alternative to the Direct Payment Rule that does not entail a "compensation deficit" and is not arbitrary, he is left with the Direct Payment Rule. However, if the Direct Payment Rule is practically impossible to apply, as McCarthy convincingly argues, and the Risk Thesis must appeal to that rule in order to accommodate the Compensation Idea, then the Risk Thesis entails what amounts to paralysis. I thus submit that McCarthy has not provided an adequate defense of the Risk Thesis vis-a-vis the Paralysis Problem. ${ }^{20}$

\section{Conclusion}

I have investigated the merits of two strategies that rights theorists may propose for dealing with the Paralysis Problem. The first strategy is to try to circumscribe the risk-imposing activities that qualify as rights infringements by qualifying the Rights Thesis with a threshold. I have argued that while the Threshold Risk Thesis can be defended against the objections considered, it is not vindicated until an adequate account of how to determine the morally relevant threshold is presented. The alternative strategy is to maintain the Risk Thesis. I considered one of the most detailed defenses of the Risk Thesis due to McCarthy and found that McCarthy's account of the possibility of combining the Risk Thesis with the Compensation Idea faces strong objections. If we accept the Risk Thesis and the claim that all rights violations generate compensation duties, then the only justified compensation rule is the Direct Payment Rule. However, this will, in line with McCarthy's own reasoning, resurrect

\footnotetext{
${ }^{19}$ See also Perry (2009) for further discussion of the relationship between McCarthy's view and negligence law. Perry takes McCarthy's account to be in tension with existing practices.

${ }^{20}$ This is not to say that there might not be other solutions to the Compensation Problem consistent with the Risk Thesis. All I have shown is that McCarthy's own proposal brings back the Paralysis Problem.
} 
the Paralysis Problem, because it is practically impossible to calculate and pay compensation for every risk-imposing action that we perform in everyday life. In short, unless a risk threshold can be determined, the Problem of Paralysis is fatal to the Risk Thesis.

\section{References}

Finkelstein CO (2003) Is risk a harm? Univ Pennsylvania Law Rev 151:963-1001

Fried C (1970) Anatomy of value. Harvard University Press

Fried C (1978) Right and wrong. Harvard University Press

Hanfield T, Pisciotta T (2005) Is the risk-liability theory compatible with negligence law? Leg Theory 11:387404

Hansson SO (2013) The ethics of risk: ethical analysis in an uncertain world. Palgrave McMillan, Basingstoke Hayenhjelm M, Wolff J (2011) The moral problem of risk imposition. Eur J Philos 20(S1):E26-E51

Kagan S (1989) The limits of morality. Oxford University Press, Oxford

McCarthy D (1996) Liability and risk. Philos Pub Aff 25:238-262

McCarthy D (1997) Rights, explanation, and risks. Ethics 107:205-225

McKerlie D (1986) Rights and risk. Can J Philos 16:239-251

Nozick R (1974) Anarchy, state, and Utopia. Basic, New York

Oberdiek J (2012) The moral significance of risking. Leg Theory 1:1-18

Perry S (2009) The role of duty of care in a rights-based theory of negligence law In: Robertson A, Tan HW (eds) The Goals of Private Law. Hart Publishing, pp. 79-112.

Railton P (1985) Locke, stock, and peril: natural property rights, pollution, and risk. In: Gibson M (ed) To breathe freely. Totowa, N.J, Rowman \& Allanheld, pp. 89-123

Scanlon T (2008) Moral dimensions: permissibility, meaning. Belknap Press of Harvard University Press, Blame Schroeder CH (1986) Rights against risks. Columbia Law Rev 86:495-562

Teuber A (1990) Justifying risk. Daedalus 4:235-254

Thomson JJ (1985) Imposing risks In: Gibson M (ed) To Breathe Freely. Rowman \& Allanheld, Totowa, N.J., pp. $124-140$

Thomson JJ (1986) Restitution, and risk. In: Rigths TJJ (ed) Some Questions About Government Regulation of Behavior. Cambridge, Mass., Harvard University Press, pp. 154-172

Thomson JJ (1990) The realm of rights. Harvard University Press, Cambridge, Mass.

Zimmerman MJ (2006) Risk, rights, and restitution. Philos Stud 128:285-311 